\title{
Introduction: In search of a third lens
}

I dreamed that God and science were lenses of meaning that humans apply on the chaos of reality, in order to make sense. This dream helped me to realize what I wanted to achieve with this book. It is a kind of quest, a quest for meaning.

Gaston Bachelard (1969a) points out that dreams and reverie are an occasion to focus on important symbols in a space less distracting and tumultuous than the everyday reality around us. Dreams are serious and should be treated seriously and sincerely. The symbols of my dream were riveting and enthralling, but they refused to tell a story. I need to stage them, to look for plots and invite characters in hope for a narrative ripple. That is why I do not stop with a tweet but go on to tell a story.

Dreams are made of symbols. People craft symbols all the time, add, alter, share and drop them. Human civilizations pass on symbols, which are elements of these very complex lenses, between generations and places. This is systemic learning. Education is not just the formal schooling we pursue in modern societies, but everything that helps us to learn and pass on knowledge between generations (Ingold, 2018). Taken together - this "everything" is the lens of my dream: a fundamental sense-making mode of society. It does not mean that they are real or not, I am not discussing the existence of God or reliability of science in this book. I am concerned about the importance of sense-making systems and, especially, in a complex world, like ours, today.

God of the Abrahamic religions (Armstrong, 1993, 2001), as well as the gods and goddesses of polytheistic religious systems (Hillman, 1997), have been a most powerful sense-making lens for humanity since ancient times. The Enlightenment added a second strong lens - a coherent and consensual system of science, based on paradigms (Kuhn, 1970). In more traditional and before-modern societies science was a part of the gods or of God. To learn, to explain, to think, was part of the divine order and there was a holy harmony or at least a significance of transcendental significance to be found or to lean one's thinking against. Monotheistic Christianity, judging all other divinity as illegitimate competition, was adversely predisposed towards systems outside of its own body - magic, witchcraft, the creatures of folk tales, etc. were regarded as coming from the evil adversary of God. Then the Renaissance split God and science apart, and the latter started to compete more openly with the former. Modernity of the last century was marked by laicization. Some 
of its institutional systems, such as state communism, proposed to get rid of God altogether. This was an era which Zygmunt Bauman described with the metaphor of systematic gardening: ordering and organizing, based on criteria of purity, classification and segregation. Useful plants were to be cared for and the weeds removed (Bauman, 1987). An ideal society was conceived of in terms of smoothness, completion, coherence. Instead of using both lenses as a combined and thus more complex set of tools for organizing understanding, the two coexisting lenses tended to compete with each other at the hands of pedantic gardeners.

In our times of crumbling structures and social institutions, marked by a systemic collapse, which Zygmunt Bauman, after Antonio Gramsci, calls the interregnum (2012), we are inundated with morose symbols: catastrophic processes and sinister characters. The dominant discourse and systemic logic want us to believe that this is all there is, that the realistic view is to accept it, as Mark Fisher (2009) so aptly depicted the spirit of capitalist realism. If things look bad, well, then, they are bad and all we can do is to brace ourselves for even worse to come. Indeed, our times have been described both in terms of philosophy (Berardi, 2019) and social sciences (Kostera, 2020) as apocalyptic, where the reality around us dissolves, inevitably, into chaos. Chaos is not fit for human survival, as human beings are sense-making creatures (Weick, 1995). In chaotic times, complex beyond our capacity to cope, there appears such a strong drive among populations of entire countries to revert to something more simple and long gone, an easier life, a utopia located in the past, that perhaps never has been, in Bauman's words - "retrotopia" (2017). But this does not work. What we desperately need is to find a new lens, to add to the older two, to be able to see better in a complex world and to make sense of the new reality.

There seems to be one rather close at hand, offering transactional rationality as a meaningful response to all major and detailed questions. However, if one takes a good look at this contemporary sense-making device, one may notice that our thinking has become colonized by a special brand of economics and management, invasive, seemingly omniscient and omnipresent (Parker, 2018; Fleming, 2019), all mighty as God used to be, authoritative as science was seen as being. This omnipresent management culture permeates public space by powerful institutions, fashions and hidden grand narratives: the self-serving business schools (Parker, 2018), the cult of the chief executive officer (Bloom and Rhodes, 2018), the predominance of a particular kind of managerial banality and normalized stupidity in public discourse (Alvesson and Spicer, 2016). In recent decades, it has entered areas that has absolutely nothing to do with management, such as values and norms of social coexistence (the culture management trend of the 1980s and 1990s, see Kunda, 1992), or even spirituality (corporate mindfulness of recent years, see Purser, 2019). Management has 
acquired the elevated status of common language, a lingua franca, a new Latin, a new common imaginarium. This is accompanied by a ceaseless dissemination of ideas and attitudes promoting a psychopathic culture of "excellence", "success" and "progress" that pollutes the symbolic environment of human emotions. It penetrates our daily lives, expectations and dreams. It breeds a spirit of sense making focused on the self, albeit very superficially.

The effect is a kind of a cultural context of narcissism (Durvasula, 2017), which is harmful to culture because it prevents the building of relationships. Relationships require mutual giving and taking, respect, friendship and the development of trust. Sociality in all shapes and forms: families, groups of friends, but also organizations, workplaces and finally big social institutions, are based on human relations. Humanity itself depends on the relationships we develop with others. Narcissism blocks mutuality: a narcissist is only able to take, not to give. Narcissistic relationships are focused on winning, seduction, sometimes on exchange, when there is potential benefit in it. But no genuine giving is possible. Reciprocity is beyond the mode of communicating because without empathy no giving is genuine. Narcissistic traits are extremely resistant to therapy: narcissists do not see the need to change, and when they become persuaded to give it a try, they will resist empathic adaptation to others. In other words, this is a dire diagnosis, not just for the narcissist but for her or his surroundings: those surroundings the narcissistic person have to bear the social and psychological consequences of the mess and to carry the shame and problems with relationships that the person constantly generates. A culture that has not only normalized but actively celebrates narcissism is not beneficent for communication or the building of relationships. It is devoid of empathy, low on human sensitivity, it thrives on a sense of entitlement and it produces blame that has to be placed on others. Yes, narcissistic culture supports a kind of individuality and inward orientation, but it lacks reciprocity and thus is devoid of a sense of balance: under its command people do not know what they are doing, how they feel, if they are not constantly showered with money, admiration and fame. Everywhere, they sense rivalry and threat, they suspect enemies behind every gesture and pose and they dedicate superhuman energy to fighting them, often truly going out of their way to make a point. It leaves human beings insatiable. This internal emptiness is often combined with other personality disorders such as psychopathy, sociopathy or Machiavellism, the so-called "dark triad". What is a problem for individuals becomes a plague for culture. It is not a good context for humans to thrive in.

However, not being a fan of the medicalization of social life or even of the language that we use to talk about it, I prefer to look for metaphors elsewhere. Narcissus was a beautiful young man from Greek myth who fell in love with his own reflection. In neoliberal society the narcissistic culture has nothing to do with love, even of oneself, and everything to do with grandiosity. To 
achieve success people and organizations seem to have lost a social thermostat, become unable to warm themselves in the light of human love and compassion. That's why they must constantly set the world on fire. I prefer to call this culture Neroism: a culture of modern Neros constantly burning Rome. The monstrous loneliness of this character makes it unenviable, while at the same time, it cannot be changed, it has to be played just like that, at the cost of communication and the Other, who is expected to give up their energy, time, work, property and ultimately their soul in order to satisfy the modern Nero. Under neoliberalism everyone - citizens, employees, managers - are supposed to take modern Nero as their role model. It becomes the measure, indeed, the metric, it defines standards and key performance indicators, offers language and sets the norms for everyone. Neroism becomes contagious, unfolds in organizations of all sectors: it spreads through relationships. Neoliberal management is making Neronic social roles, defined by what looks like the narcissistic personality disorder, not only normal and universal, but even obligatory. Everything is suffused with the pattern: mass culture, education and above all business schools from all of higher education get infected, as Martin Parker (2018) argues in his book entitled Shut Down the Business School.

Neroism is spreading and becomes the normal language and symbolism via media, press, common sense and pop culture. For many people it has come to mean a sorry kind of realism, the moral glue keeping together late capitalism that claims exclusivity and inevitability for itself (Fisher, 2009). To imagine a reality where cooperation may be more important than individual success, where learning can be a collective effort, not individual stardom, where the common good is important and valued - all that is unconceivable: at best outdated, outmoded, immature or just plainly unthinkable. We talk about ourselves, about our lives, about our goals and desires, as if we were all little modern Neros, not because we suddenly have become like this, devoid of empathy and egoistic, but because it is the only language available. Language gives shape to the imagination and creates reality. Nowadays it is through language that a void keeps entering our guts, and we feel compelled to fill it with constant "successes", with consumption, food, alcohol, and we start to act accordingly: without inhibitions, without empathy, because "there is no alternative".

Mats Alvesson's book The Triumph of Emptiness (2014) unmasks the unmitigated prevalence of grandiosity in contemporary organizational life. Gigantomania has been defining management in the last decades, and it became an obligatory language for the whole world. Everyone must be "top word class", everything is submitted to rankings, measured and compared, patients and students assess doctors and teachers in systems very much like booking.com ratings of tourist attractions, restaurants, hotels. We are all busy polishing our CVs with care and effort, we dedicate so much time to it, that 
there is no time left for anything else, such as good work or having a life. But it has no content; do we still know what it would look like if it existed? So, only surfaces matter. Everyone is sitting at an eternal poker table and bluffing their way through an endless hold'em game, no one is in any hurry to check, because we are all complicit, this is all there is to the game. Lies have become emancipated and gained a new noble name: "post-truth". The façade is everything, it has to be everything, it must be everything, but it does not bring much into our lives, into the lives of organizations, when it is suspended upon a void.

Have no doubt, this is no unfortunate side-effect, not an error. It is the way it is supposed to be: the current management canon. Shiny surfaces are illusionistic tricks - the original meaning of the word prestige is just that, a trick - so detached from meaning that people have ceased asking what they are supposed to mean. Organizations suck us dry of energy and take away our will to live (Fleming, 2015), without bringing anything socially useful or good for the planet - indeed, the opposite is true, we are now living in times when human-caused climate change is truly threatening the life of the planet (Klein, 2015). And yet the obligatory management style is still based on the same assumptions which have caused this wreckage: what matters is only measurable economic growth, consumption and externally defined "transparent" standards, assessments and objectives. Fraud and exploitation are as old as business, indeed, much older, but there is a new quality to the misery and that is the self-righteousness of management turned universal. It spreads and embraces the totality of human life. Mats Alvesson (2014) speaks of a totalization of a language, where words have turned into slogans, which have turned into magical formulas. "Customer satisfaction", "sustainable development", "emphasis on human resources" and the ubiquitous "excellence" mean absolutely nothing at all. And nobody expects them to, not anymore.

The response to these slogans is cynicism, depression, passivity or anger, fury even, including the sordidly hateful screams that fill up our public space these days. Some certainly come from the throat of psychopaths, but much is due, perhaps, to a lack of other languages. Humans have been educated and persuaded to use a language that is divorced from feelings of empathy and social sensitivity. Instead, we have been trained that the only adult language is Neroism, suffused with metaphors promoting individualism and competition (Lackoff, 2014), propagating gigantomania and emptiness.

The language of Neroism delivers morbidity to communities and organizations, destroying the joy of life and the meaning of work. In small communities it infects networks and teams. In large organizations it is managed top-down. Neroism literally trickles down the hierarchy, from chief executive officer via managers and human resources equipped with sadistic emails, through middle management, to the very bottom and even lower, to the precariat who will never own astounding supercars or fly business class, and yet they, too, 
identify with this lifestyle and its values, instead of taking to the barricades together with their comrades and demanding decent pay for a decent job. Only Neroism trickles down, not wealth, as it was promised us in the 1980s by neoliberals in their talk about the "trickle-down effect" (Streeck, 2016). Wealth was supposed to fall down from the table of the rich to the lower levels of social structure and in maybe 10, 15 years, all of us would be just like Blake Carrington from the popular Dynasty TV series. ${ }^{1}$ We are not. We will never be. The Carringtons of our times ceased to be like the Carringtons of the series, who, after all, were fairly human; even the baddie of the family, Blake's ex-wife, Alexia, was more interested in people, for good and for worse, than in shareholder value tables. Instead, they became Trump, Murdoch, Zuckerberg and Musk, completely detached from the rest of humanity and nature, never satisfied with what they have, the 63 people who own more than the poorer half of Earth's population. Their wealth is constantly growing, at our expense. So Neroism trickles down. First, the once fairly flesh and blood capitalist patriarch (or, more rarely, matriarch) became a Nero made of gold. And then we all became Neros, but Neros of dust, of smoke, thrift shop Neros. We talk a language that has been Neroized and our social imagination leaves us without other possibilities.

This culture is focused on the individual but is ferociously superficial and never penetrates the surface into the depth of the soul: indeed, it has done away with anything more than skin-deep. James Hillman (1979) warns about the risk of losing the ability to connect different domains of experience. Perception of what is outside us brings the potential to be linked, to reverberate with an internal truth (Hillman, 1997).

When the invisible forsakes the actual world, as it did when it deserted Job, leaving him plagued with every sort of physical disaster (Job's midlife crisis), then the world no longer sustains life because life is no longer invisibly backed. Then the world tears you apart. Isn't that the simple lesson taught by the withering and collapse of tribal cultures once they are robbed of their spirits in exchange for goods? (Hillman, 1997, p. 111)

The organizational and managerial symbolism invading and colonizing contemporary culture looks sinister, blinding, rather than enlightening. It focuses inward, on the individual but does not lead to knowing oneself or to the development of an imaginative mind. It makes claims to helping to see how to control organizations but it does not support communication, without which organization is impossible (March and Simon, 1958). However, it is an exceedingly pervasive symbolism. It lulls us to accept that late capitalism, driven by morbid dynamics, is inevitable (Fleming, 2019). It is a cancerous imaginarium, as it has coopted many of the potential paths out of it, such as the very idea of looking for something new. The managerialist world-media, 
books, learned articles, education programmes at all levels - is filled with claims of the incessant discovery of novelty: innovation and improvement. The path to improvement is also given and monopolized by Neroism and productivity. It is touted as an individualistic project said to be rooted in "creativity" understood as a kind of manufacture and invention, and leading to the appearance of a new brand or marketable product.

So, yes, the potential of the managerial discourse to become a sense-making lens seems overpowering nowadays but its effects are ominous. And it is precisely because of this sinister pervasiveness that I intend to take a good look at it in this book. It cannot, obviously, be disregarded, but it can be recontextualized. A massive reconstruction of the idea of "management" lies within its context - that of organizing and organizations, advises Martin Parker (2018). Let us remember that managing can be a role based on the logic of caring (Gabriel, 2009), talking, listening. Managers are, today, not paragons of compassion, but this is not due to their inherent role but to the noxious values and images of "[c]ontemporary Western culture [that] favours the narcissistic personality, characterized by inner emptiness, need for reassurance and anxiety over an inability to create a meaningful world with which to establish relations" (Gabriel, 1999, p. 190).

A broader view - or one directed further and deeper, into the rules of the game, the big collective invisible - is necessary to liberate organizing and managing from the mechanisms of "wreckage economics" under late capitalism so aptly described by Peter Fleming (2017). The system has run out of healthy self-restoration functions and is relying on coercion, excessive rule and regulations, and other increasingly morbid remedies, which perpetuate the fall, rather than offer a way out of the trap the world has found itself in (Bauman, 2017). We may not have any hope in the system's ability to save itself, as Peter Fleming convincingly argues in his The Worst Is Yet to Come (2019), but there might be hope yet for us thanks to the human ability to organize which does not, indeed, presume Neroism.

So, back to the quest for the third lens. God, science, not managerialism, so what? What comes next, as a more welcome addition? This book does not aspire to answering this question, it lies far beyond any scientific or even prophetic power. What I invite the reader to do with this book, is to join in the questing by imagining, dreaming and organizing. I propose to take organizational and managerial symbolism with us on this journey, as it indeed is a common language and as such can be of great use if we reclaim it, occupy it. I suggest that we use it to dive into our collective imagination which, following Gaston Bachelard, the great philosopher of imagination understood as human right (1990). Like Bachelard, I shall consider it in spatial terms (Bachelard, 1969b). 
The continuity of the life process is social, and is provided by education, claims Tim Ingold (2018) referring to the pragmatist philosopher John Dewey. Communication and sharing, the passing on of symbols and ideas are brought together, acquire an increasing complexity. Currently the need for complex ideas is urgent and profound if we are to escape from the sinister downward spiral of the system's morbidity (Fleming, 2019). To act together is necessary, as is consciousness - not mindfulness (Purser, 2019). To once again cite Bachelard, the engagement of consciousness is by no means a private matter: "A consciousness associated with the soul is more relaxed, less intentionalized than a consciousness phenomena of the mind. Forces are manifested in poems that do not pass through the circuit of knowledge. The dialectics of inspiration and talent become clear if we consider their two poles: the soul and the mind" (Bachelard, 1969b, p. xvii).

This is a book about inspiration. Very definitely, it is not a book on workplace spirituality. Rather, it focuses on the imagination and on imagining. The much sought-for third lens is connected to setting imagination free, perhaps it gets born out of it, as a way of getting closer to the possible yet unattainable future. I very much agree with Franco "Bifo" Berardi (2019, p. 141) that we need to "predispose [our] mind[s] to the second coming [of communism]": our minds are hopelessly entangled in a connective syntax that blocks imagination and understanding of anything beyond capitalism. Berardi believes that this will be a second coming of communism. I am not so certain about what it will bring (although my heart is set on some kind of anarcho-socialism, or what happened on Anarres in Ursula Le Guin's (1974) The Dispossessed, after the novel ended). But whatever it will be, it will have to be an exceedingly complex system, where at least three powerful sense-making lenses will be in active use. To keep chaos away but complexity close to heart.

\section{NOTE}

1. Dynasty was a long-running television show, popular in many countries in the 1980s and 1990s. It presents the everyday life of a wealthy Texan family, the Carringtons, with its respectable but hegemonic patriarch, Blake, his younger wife Krystle, and his two children: the openly gay Steven and the slightly wayward Fallon, with respective exes, lovers and friends. 